\title{
FAMÍLIAS, ANIMAIS DE ESTIMAÇÃO E CONSUMO: UM ESTUDO DO MARKETING DIRIGIDO AOS PROPRIETÁRIOS DE ANIMAIS DE ESTIMAÇÃO
}

Family, pets and consumption: A study of marketing directed to pets owners

\section{Familias, mascotas y consumo: un estudio de marketing dirigido a los propietarios de mascotas}

\author{
Lavínia Davis Rangel Pessanha ${ }^{1}$ \\ Roberto Luís da Silva Carvalho ${ }^{2}$
}

\section{Resumo}

Analisamos o efeito da comercialização generalizada de produtos indústria de cuidados para animais sobre o vínculo entre pessoas e animais nas famílias. Estudamos propagandas para proprietários de animais de estimação veiculados na Internet no Brasil. O marketing estimula a humanização dos animais a fim de induzir o consumo, o que não impede o surgimento de afetos e sentimentos genuínos na convivência diária de pessoas e animais nas famílias, tendo em vista o processo de antropomorfismo sentimental.

Palavras-chave: consumo, propaganda, animais de estimação, famílias, antropomorfismo.

\begin{abstract}
We analyze the effect of the widespread marketing of by pet care industry products on the human animals bond in families. We study the advertisements for pets owners broadcast on the Internet in Brazil. Marketing stimulates the animal humanization in order to induce the consumption, which does not preclude the emergence of genuine feelings and emotions in people and animals daily living in families, due to the sentimental anthropomorphism process.
\end{abstract}

Keywords: consumption, marketing, pets, family, anthropomorphism.

\footnotetext{
${ }^{1}$ Cientista social, com doutorado na área de sociologia, pesquisadora titular da Escola Nacional de Ciências Estatísticas. Professora do Mestrado em Estudos Populacionais e Pesquisas Sociais. E-mail: lavinia.pessanha@ibge.gov.br

${ }^{2}$ Mestre em Estudos Populacionais e Pesquisas Sociais. Professor do Instituto de Educação, Agricultura e Ambiente, Universidade Federal do Amazonas. E-mail: roberto_carvalho@ufam.edu.br
} 
Famílias, animais de estimação e consumo: um estudo do marketing dirigido aos proprietários de animais de estimação

de Lavínia Davis Rangel Pessanha e Roberto Luís da Silva Carvalho

\section{Resumen}

Se analizó el efecto de la amplia comercialización de productos para la industria del cuidado de los animales sobre la relación entre personas y animales en las familias. Se estudiaron los anuncios para los propietarios de mascotas disponibles en la Internet en Brasil. Marketing estimula la humanización de los animales para inducir el consumo, lo que no impide el surgimiento de genuinos sentimientos y emociones en la vida diaria de las personas y los animales en las familias, teniendo en cuenta el proceso de antropomorfismo sentimental.

Palabras-clave: consumo, marketing, animales de estimación, familias, antropomorfismo.

\section{INTRODUÇÃO}

A antropomorfização e a humanização de animais, bem como o amor e a preocupação com o sofrimento animal são questões que aparecem frequentemente nas notícias veiculadas pela mídia. O objetivo deste trabalho é apresentar uma perspectiva de análise para a relação entre as pessoas e seus animais de estimação nas famílias contemporâneas, buscando entender o fenômeno, a partir do discurso do marketing do setor. A profusão de propagandas direcionadas para proprietários de animais de estimação difundidas causa curiosidade tendo em vista o modo como se dirigem à pessoas e famílias. É comum que as pessoas se referiram aos seus animais como se fossem seus familiares, animais são frequentemente tratados com afeto próprio àquele destinado aos membros da família no ambiente privado como no cotidiano informal e nos momentos de lazer.

Nas ruas, o resultado da "indução" ao consumo é visível, uma vez que os cães, principalmente, portam em seus corpos uma vasta gama de adornos e acessórios que por vezes parecem "perfeitamente dispensáveis à sua condição animal” (coleiras coloridas, laços, gravatas, sapatos, vestidos, saiotes e outros). Estes adornos são muitas vezes semelhantes aos utilizados pelas pessoas que os portam. Em propagandas veiculadas na televisão é comum assistirmos a antropomorfização de animais, que falam e agem como se fossem pessoas. Por isso, apresentamos uma perspectiva de análise que permite entender a concomintante antropomorfização afetiva que se dá no ato de consumo, entre os donos e os animais de estimação. 
Famílias, animais de estimação e consumo: um estudo do marketing dirigido aos proprietários de animais de estimação

de Lavínia Davis Rangel Pessanha e Roberto Luís da Silva Carvalho

\section{ANIMAIS DE ESTIMAÇÃO, PESSOAS E ANTROPOMORFISMO}

Um animal é considerado de estimação quando tem permissão para livre acesso às residências, recebe nome pessoal e individualizado e não será utilizado como alimento (THOMAS, 2001). Deste modo, podemos tomar o animal de estimação como membro da família quando ele é assim tratado pelas famílias com as quais interage, bem como nos circuitos de consumo aos quais está integrado. Na cultura ocidental, o tratamento especial dispensado aos animais de estimação constitui a exceção que comprova a regra segundo a qual ser pessoa é sinônimo de ser humano, (INGOLD, 2000 apud BEVILAQUA, 2011).

Sabemos que a percepção de animalidade como espécie e como condição distinta da singularidade humana vem sendo desafiada nas últimas décadas (WOLCH e EMEL, 1998; INGOLD, 1998), e nesse sentido é importante ter em conta que animais de estimação são híbridos de natureza e cultura (LATOUR, 1993). Haraway (2003) considera humanos e cães como espécies companheiras.

Autores como Singer (2004), Reagen (2001) e Francione (2007) desenvolveram concepções filosóficas críticas aos pressupostos utilitarista, antropocentrista e especista do relacionamento entre homens e animais, que originaram um tipo de mobilização social e ativismo político voltados para o bem-estar, o abolicionismo e a defesa dos direitos dos animais.

Contudo, o antropocentrismo permanece inerente a concepção de humanidade na qual se baseiam as concepções da ciência moderna (SILVA, 2011), do direito ocidental (BEVILAQUA, 2011) e do capitalismo. Para além dos aspectos ético-filosófico-jurídicos envolvidos no tratamento dos animais como seres passíveis de propriedade e de mercadorização, buscamos entender o modo como o marketing da indústria se apropria das mudanças de percepção, atitude e mobilização em torno da causa animal, criando novos mercados e revigorando os circuitos de consumo já existentes.

Pessoas que tem animais de estimação os distinguem das demais pessoas, a questão é como este relacionamento afetivo no âmbito das famílias produz a antropomorfização. Da mesma maneira, as empresas de bens e serviços para animais de estimação, mesmo cientes da distinção animais e humanos, produzem campanhas de marketing onde estas duas categorias se confundem, tendo em vista fortalecer a motivação para a compra de seus produtos por parte dos potenciais consumidores. 
Famílias, animais de estimação e consumo: um estudo do marketing dirigido aos proprietários de animais de estimação

de Lavínia Davis Rangel Pessanha e Roberto Luís da Silva Carvalho

Nas ciências humanas se encontram artigos cujo objetivo é responder à questão: por que as pessoas amam os seus animais de estimação? (ARCHER, 1997; WALSH, 2009a). Entre os temas abordados estão o tipo e a intensidade do vínculo entre as pessoas e seus animais de estimação, particularmente o vínculo entre seres humanos e cães (ARCHER, 1997). O significado da relação entre pessoas e animais de estimação, bem como o papel dos pets na dinâmica dos sistemas familiares é também discutido (WALSH, 2009a, 2009b). $\mathrm{O}$ afeto entre pessoas e animais de estimação e o modo como esse sentimento se expressa na esfera do consumo é tratado por sociólogos, geógrafos, psicólogos também por especialistas de marketing ${ }^{3}$.

Belk (1988) e Sanders (1990) utilizam o interacionismo simbólico para o entendimento da subjetividade dos agentes nas relações com animais de estimação. Sanders (1990) enfatizou a importância dos objetos materiais como representações simbólicas, sendo que neste contexto, "coisas" ou bens seriam veículos simbólicos através dos quais as pessoas estendem seu "eu social". Entre as categorias de coisas ou seres, entendidos como uma extensão da pessoa, estariam os animais de estimação (BELK, 1988: 155-156). A escolha do animal de estimação seria moldada pela personalidade do dono; sendo uma representação concomitante de membro da família e objeto de domínio. O animal de estimação denotaria significações - conforto, proteção, amor, saúde, companheirismo e um alargamento da definição pessoa - como nenhum outro elemento da cultura de consumo.

Berry (2008) avança no entendimento das relações entre pessoas e animais a partir do interacionismo, inserindo na análise uma analogia das assimetrias de poder que ocorrem nas relações humanas. Desta forma, afirma que

\footnotetext{
"do mesmo modo como os humanos mais poderosos (...) impõem, conscientemente ou não, seus valores aos menos poderosos; os humanos são indiscutivelmente livres para fazerem suas escolhas para mudarem a si próprios, enquanto os não-humanos estão sujeitos às escolhas dos humanos tanto como espécime, como pelas suas aparências" (SOCIETY AND ANIMAL, 16, 2008: 82).
}

Ressaltamos que o animal de estimação não enuncia "desejos ou necessidades" através da fala, nem mesmo realiza atos de compra, pois quem o faz é o seu dono, resta saber a quem pertenceriam estes “desejos e necessidades”. É neste sentido que o animal de

\footnotetext{
${ }^{3}$ Para uma visão do modo como pesquisadores de distintos campos de conhecimento abordam o tema dos animais de estimação e consumo, consultar a publicação: “Animal Companions, Consumption Experiences, and the Marketing of Pets: Transcending Boundaries in the Animal-Human Distinction”. Journal of Business Research Vol.61, Issue 5, Pages 377-586 (May 2008).
} 
Famílias, animais de estimação e consumo: um estudo do marketing dirigido aos proprietários de animais de estimação

estimação pode ser visto como uma extensão da pessoa. O marketing voltado para a venda de produtos para animais de estimação utiliza esta fusão, e difunde mensagens nas quais "desejos e necessidades" de proprietários de animais de estimação se confundem com aqueles que seriam próprios dos animais.

É neste sentido que as empresas do setor de cuidados para animais de estimação se utilizam da humanização como indutora do consumo. É na interface entre empresas e pessoas entendidas genericamente como consumidores que atua o marketing, como instrumento de comunicação e como processo social (ROCHA e CHIRSTENSEN, 2008).

O antropomorfismo é definido como uma atribuição de estados mentais humanos (pensamentos, sentimentos, motivações e crenças) a animais não humanos (SERPELL, 2003), sendo esta uma característica quase universal, presente entre os 'cuidadores' de animais.

$\mathrm{O}$ antropomorfismo é um processo contra-intuitivo, ainda que pareça um processo natural (BOYER, 1996) ou uma compreensão apriorística de senso comum, sendo a imputação de estados mentais antropomorfizados aos animais, quando tomada como uma afirmação categórica (KEELEY, 2004), questionada no meio científico (REES, 2007).

Nesta perspectiva, os proprietários de animais de estimação se identificam afetivamente com seus animais e se relacionam com os mesmos como membros da família. Neste caso, animais recebem alguma forma de carinho e proteção, chegando, em alguns casos, a serem tratados como "filhos" (COHEN, 2002; CORNWELL, WAMWARAMBUGUA e NICOVICH, 2008; HILL, GAINES e WILSON, 2008; HOLBROOK, 2008; KENNEDY e MCGARVEY, 2008; KONECKI, 2007; MOSTELLER, 2008; SHELL, 1986). No contexto familiar, o papel dos animais seria o de satisfazer necessidades de companhia, amizade, amor incondicional e afeto (DOTSON e HYATT, 2008). O que distinguiria a relação de amor das pessoas por animais na sociedade pós-industrial contemporânea seria a intensidade de investimento financeiro, emocional e cultural em animais de estimação (NAST, 2006a, 2006b).

Deste modo, a identificação afetiva entre as pessoas e animais de estimação é, em geral, é aceita pela sociedade. Ademais, grande parte dos neurocientistas reconhece que animais de estimação têm emoções básicas tais como prazer, medo, raiva e excitação que forneceriam a base para a motivação (VLAHOS, 2008; PANKSEPP, 2004).

A identificação sentimental entre homem e animal se torna um instrumento de marketing, tendo em vista estimular o consumo de produtos como demonstração de amor, 
Famílias, animais de estimação e consumo: um estudo do marketing dirigido aos proprietários de animais de estimação

afeto e cuidado pelos animais. As empresas globais do setor buscam novos mercados através da humanização, sendo esta uma ação orientada também para países com economias em crescimento o orientada também para países com economias em crescimento. O objetivo seria induzir mudanças de atitudes do consumidor no sentido de acentuar o papel dos animais como 'companheiros leais' e 'membros da família'. As atitudes dos consumidores em relação a cães e gatos seriam moldadas por campanhas educativas e de sensibilização, bem como por atividades de marketing integrado, que podem incluir feiras, criação de clubes, promoção de eventos "esportivos", co-patrocínio de campanhas de vacinação gratuita e lançamento de publicações, entre outros (NAST, 2006a).

A humanização tornaria mais enraizada a necessidade de melhoria da qualidade de vida dos animais de estimação, e provavelmente se tornará o fator dominante por trás da compra de produtos (NAST, 2006a). As empresas do setor de ração animal foram as primeiras a explorar essa tendência, e o conjunto indústria atribui grande parte da resistência à crise econômica global à estratégia de humanização. Simultaneamente, há o surgimento de novos mercados pela "replicação" de serviços e bens originalmente criados para pessoas. A humanização está por trás da emergência da moderna farmacologia para animais de estimação do crescimento desta indústria (VLAHOS, 2008).

Donos de animais de estimação cada vez mais veem seus animais como parte da família e esta despesa não é restrita a itens essenciais como alimentos, e inclui itens, como a saúde animal e suplementos dietéticos, cosméticos e viagens, o que cria oportunidades de mercado e dá suporte ao crescimento do setor (EUROMONITOR, 2011: 1).

Assim, podemos perceber que a estratégia de marketing da indústria de cuidados com animais é compatível com o processo de apropriação e substituição de tarefas ocorrido no setor da agricultura ocorrido no século XX (GOODMAN, SORJ e WILKINSON, 1990). A humanização pode ser entendida como "um novo nome para a antiga tendência de se verem animais como versões peludas de nós mesmos" (VLAHOS, 2008: 452). As estratégias de marketing para o fortalecimento da percepção antropomorfizada do animal de estimação no cotidiano das pessoas e famílias pretende "induzir" o consumo de produtos ofertados pela indústria.

\section{INFORMAÇÃO, MARKETING E CONSUMO NO ESPAÇO VIRTUAL}


Famílias, animais de estimação e consumo: um estudo do marketing dirigido aos proprietários de animais de estimação

De acordo o Euromonitor (2011), a América Latina foi "o astro do mercado global de cuidados para animais de estimação (...) durante o período 2005-2010”. A proporção das vendas de produtos para cuidados de animais de estimação no mercado latino-americano subiu de 7,6\% em 2005 para 10,2\% em 2010 em relação do mercado mundial. Em 2010, o Brasil foi considerado o maior mercado na região, seguido pelo México e Argentina, já se constituindo o segundo mercado mundial para produtos destinados aos pets.

A primeira situação a ser observada é a do animal como mercadoria e objeto de compra e venda. Não há como saber quantos animais de estimação são comprados, uma vez que nem todos são adquiridos pela família. É conveniente lembrar que não há proibição à comercialização cães e gatos no Brasil. Uma vez integrados à rotina familiar, estes se tornam um veículo dinamizador dos mercados.

$\mathrm{Na}$ alimentação, existem cerca de quinhentas marcas e oitenta fabricantes de alimentos para cães e gatos (CARCIOFI, TESHIMA, BAZOLLI, BRUNETTO, VASCONCELLOS, PEREIRA e OLIVEIRA, 2009). Os produtos alimentícios incluem as rações industrializadas, rações especiais, alimentos caseiros e alimentos classificados como petiscos. As rações industrializadas são classificadas como: econômica, padrão, premium e super-premium, de acordo com os nichos de mercado. São encontradas linhas que podem ser denominadas nutracêuticas e funcionais (lights e diets) e aquelas destinadas a raças específicas. É possível encontrar uma ração “adequada” para cada tipo de cão ou gato.

$\mathrm{Na}$ área de medicamentos, encontramos os grandes laboratórios voltados para o desenvolvimento de fármacos. Além daqueles tradicionalmente desenvolvidos para animais, os medicamentos incluem agora tratamento para doenças de grande complexidade, e mesmo para aquelas anteriormente diagnosticadas em humanos, como obesidade, transtorno depressivo e disfunções cognitivas (VLAHOS, 2008). Os serviços da medicina veterinária e outras áreas afins englobam uma gama diversificada de serviços especializados, tais como odontologia, cardiologia, radiologia, comportamento animal, entre outras. Conjuntamente, seguros de saúde fornecem serviços veterinários mediante pagamento mensal por parte do proprietário, para acesso a especializações anteriormente disponíveis à medicina humana.

$\mathrm{Na}$ área de higiene animal, os serviços incluem banho e tosa higiênica e limpeza de tártaro. Os principais benefícios procurados pelos proprietários em relação ao xampu seriam: limpeza técnica (limpeza, não causar alergia e manter o animal livre de pulgas); embelezamento técnico (perfume do produto, volume e maciez propiciado ao pelo do 
Famílias, animais de estimação e consumo: um estudo do marketing dirigido aos proprietários de animais de estimação

de Lavínia Davis Rangel Pessanha e Roberto Luís da Silva Carvalho

animal) e imagem e marca (capacidade de desembaraçar, branquear e/ou realçar cores) (SOARES e CARVALHO, 2004). Os produtos incluem sabonete, xampu, condicionador, escova, rasqueadeira, pente, secador, absorvente higiênico, lenço umedecido, pasta e escova dental, cortador de unhas, coletor de fezes. Em muitos casos os produtos e/ou serviços do setor de higiene para animais de estimação são criados semelhantes aos destinados às pessoas, como por exemplo, a calcinha higiênica para cadelas, "porta caca" (bolsa de transporte estilizada de dejetos estilizada), porta sacos para dejetos no formato de coração.

Há também produtos disponíveis aos que pretendem "acompanhar as necessidades do mundo moderno, a rapidez nos serviços, bem como a praticidade dos maquinários utilizados no setor". Em matéria veiculada em site ${ }^{4}$, verifica-se que é possível utilizar uma "máquina de secagem e higienização de cães", na qual o animal é acondicionado em uma caixa com jatos de ar quente e temperatura controlada, com objetivo de proporcionar a 'secagem e higienização da pelagem' de 'forma rápida' evitando o 'estresse do animal'. A máquina "disponibiliza um sistema de luz infravermelha, aplicado durante a secagem que ajuda a evitar as doenças de pele", similarmente àqueles utilizados nos secadores para cabelos humanos.

Constatamos que os mesmos conceitos utilizados no mercado de produtos destinados às pessoas são utilizados no marketing de produtos animais. Exemplo disso é o sanitário para animais, disponibilizado por empresa ${ }^{5}$ que atenderia as demandas de higiene do cão. A nosso ver, o importante no caso é denotar limpeza e beleza no produto ofertado, que em nada remete a fezes e urina. O "acessório fêmea" simula um "banheiro de verdade", de modo a deixar "o sanitário mais charmoso" "delimitando melhor o seu espaço, sendo que as cores podem combinar com as bandejas do sanitário.” Já o "acessório macho é indispensável para quem tem um cão macho em casa”, sendo que o seu desenho representa um pequeno hidrante de rua.

A hotelaria para cães e gatos é um mercado em ascensão. Neste segmento, há diversificação da hospedagem para animais e a ampliação do número de hotéis que aceitam animais junto com seus hospedes (AFONSO, BERDASCO, MEDEIROS e REJOWSKI, 2008). Evidentemente, o foco não está somente relacionado ao lazer do animal, pois os produtos ou serviços são projetados também para proporcionar tais sensações aos

\footnotetext{
${ }^{4}$ Disponível em <http://www.petbrasil.com.br/lanca155.asp >. Acessado em 27/10/2010.

${ }^{5}$ Disponível em <http://www.pipidollys.com.br/>. Acessado em 27/10/2010.
} 
Famílias, animais de estimação e consumo: um estudo do marketing dirigido aos proprietários de animais de estimação

de Lavínia Davis Rangel Pessanha e Roberto Luís da Silva Carvalho

proprietários.

No ramo da moda, se ofertam roupas para vestir animais de estimação com ilustrações de desenhos animados e fantasias, da mesma maneira como as pessoas fazem com seus filhos, num evidente antropomorfismo sentimental. Em determinado site ${ }^{6}$ são oferecidos lacinhos similares àqueles para os cabelos de meninas; medalhas para enfeitar coleiras estilizadas, com desenhos de cãezinhos, gatinhos, ossinhos, bolinhas e ossos para cães. No estudo das imagens disponibilizadas pelas empresas na internet, é visível a intenção de despertar do prazer, alegria, emoção, sentimentos necessidades atribuídos pelo proprietário ao seu animal de estimação.

Vários exemplos demonstram que os produtos procuram atender os desejos dos consumidores através de necessidades atribuídas aos animais, como: casinha para cão em formato de castelo, festas de aniversário para animais de estimação (LEITE, 2007), brinquedos parodiados ou a utilização de designs originalmente criados para embalar produtos para crianças.

$\mathrm{Na}$ área de embelezamento são encontrados os serviços de tosa artística, com produtos de amplo leque, tais como perfume, tonalizante de pelos, cosméticos especializados, sapatos, roupas, chapéus, laços, gravatas e afins, fantasias, óculos, joias e bijuterias, capa para chuva, unhas postiças, entre outros. Tudo visando o embelezamento dos animais de estimação de acordo com o grau de requinte dos proprietários. Neste segmento, bens e serviços de uso tradicionalmente humano adentram o mercado pet, replicando desse modo experiências de consumo. Várias empresas oferecem serviços especializados que buscam explorar a beleza do animal de estimação, entre eles a utilização da "escova de chocolate", "cauterização", "chapinha", entre outros. Petty (2008) debate o mercado de marcas para os animais de estimação através da noção de paródia, aqui entendida como uma aplicação lúdica do antropomorfismo, através da identificação das pessoas com as marcas como: cães utilizando roupas, brinquedos e acessórios de marcas famosas.

Como foi possível observar, há uma crescente oferta de bens e serviços nas diversas áreas do mercado de cuidados para animais de estimação, particularmente os de alimentação e saúde, que geram novas oportunidades para empresas do setor. Os gastos pelos proprietários (propensão ao consumo) difeririam segundo a importância que os

${ }^{6}$ Disponível em <http://www.conforpet.com.br/prod-veterinarios.html>. Acessado em 28/02/2011. 
Famílias, animais de estimação e consumo: um estudo do marketing dirigido aos proprietários de animais de estimação

mesmos dariam à "qualidade de vida" de seus animais de estimação (CAVANAUGH, LEONARD e SCAMMON, 2008). É neste sentido que o antropomorfismo é um fator dinamizador do mercado de produtos para animais de estimação, principalmente no que tange aos cuidados veterinários e alimentos, e tem sido utilizado pelas campanhas de marketing veiculadas na mídia, inclusive no Brasil.

Há similaridade entre os valores que orientam as ações da indústria voltada para animais de estimação e aqueles que orientam os mercados de produtos para humanos, tais como a conveniência, o prazer e a saúde. É necessário ter em conta que, neste mercado, há pouco espaço para inovação na esfera da produção e do marketing especificamente brasileiros, tendo em vista que os grandes fornecedores serem os mesmos que abastecem o mercado global. E deste modo, assim como há antropomorfismo e mimetismo entre valores que regem ambos os mercados, há a transposição das tendências internacionais de marketing e das estratégias de comunicação com o consumidor.

Numa das principais revistas de divulgação do setor para produtores, revendedores e consumidores da indústria pet $^{7}$ norte-americana há o reconhecimento de que a indústria intenciona fornecer rações que pareçam familiares aos membros da família humana, tendo em vista gostos e desejos dos consumidores (humanos) e a percepção do animal como membro da família. Na visão de definidores de tendências do setor, isto não significaria reduzir o consumidor a um 'tolo', uma vez que a humanização (entendida aqui como atribuição de características humanas a criaturas não humanas), não deveria ser considerada de modo literal pela indústria, mas como uma expressão de tratamento devotado e comprometido ao animal de estimação, de modo semelhante ao que é despendido com os demais membros da família. ${ }^{8}$ Ainda assim, os discursos aqui apresentados mostram uma abordagem simplificada da racionalidade deste consumidor de produtos.

Outro aspecto a ser considerado nos anúncios analisados é o tratamento dispensado aos animais de estimação. Textos e imagens apresentam o animal como uma extensão da personalidade de seus proprietários, de modo compatível com a abordagem interacionista (BELK 1988; SANDERS, 1990). Ademais, em muitas imagens analisadas, particularmente as de tratamentos clínicos, higiene e embelezamento, os animais são visualizados na condição de objetos submetidos à vontade humana, numa visível assimetria de poder

\footnotetext{
${ }^{7}$ Disponível em <http://www.petfoodindustry.com.November 2011>. Acessado em 02/12/2011.

${ }^{8}$ Disponível em <http://www.petfoodindustry.com.December 2011>. Acessado em 02/12/2011.
} 
Famílias, animais de estimação e consumo: um estudo do marketing dirigido aos proprietários de animais de estimação

(BERRY 2008).

\section{PESSOAS, ANIMAIS E CONSUMO: O ANTROPOMORFISMO NA ESFERA DAS FAMÍLIAS}

Pelo exposto, é necessário reconhecer que a identificação entre a pessoa e o animal de estimação está presente no ato de consumo. O utilitarismo foi aqui aceito como um instrumento de marketing indutor de consumo pela indústria ao fortalecer a humanização e a identificação do proprietário com os animais de estimação. Animais não compram e não expressam 'necessidades ou desejos' a serem realizados através da compra e suprimento de produtos. As propagandas direcionadas aos proprietários trabalham esta informação de modo a (con)fundir animal e pessoa. A informação é direcionada a um proprietário de animais idealizado, e o discurso é construído de modo a despertar ilações com a finalidade de vender o produto.

Contudo, este tipo de consumo não pode ser explicado tão somente do ponto vista utilitarista. Na sociedade de consumo moderna, o ato de comprar pode ser compreendido também como expressão de amor (MILLER, 2002). Assim, do mesmo modo que pessoas e famílias fazem compras no cotidiano como um rito de estreitamento dos laços de afinidade e parentesco, as compras de bens para animais denotam estima e a busca fortalecimento do laço afetivo com o animal. Esta associação é mais evidenciada nas situações em que o animal é identificado mais como uma pessoa do que um animal, e nos casos em que estes são tratados como substitutos dos filhos ou como membros da família (HILL, GAINES e WILSON 2008; MOSTELLER, 2008).

Assim, seria até mesmo possível considerar de outro modo a atitude de comprar o animal de estimação, crescentemente criticada do ponto de vista ético ${ }^{9}$. Não há como deixar de reconhecer que ao comprar um animal, particularmente aqueles de raça e com pedigree (um documento registrado que é um certificado de origem), a pessoa procura prestígio e distinção através do animal adquirido. Contudo, o ato de compra de um animal pode decorrer de um impulso amoroso, tal como nos relacionamentos entre pessoas. A compra poderia decorrer de um longo 'namoro' com o animal pretendido, e em cada situação, seu resultado é imprevisível (OLIVEIRA, 2006).

\footnotetext{
${ }^{9}$ Do ponto de vista ético crítico, esta atitude não pode deixar de ser considerada com expressão de uma afetividade homocênctrica, narcísica e egoísta (BARLETT: 2007).
} 
Famílias, animais de estimação e consumo: um estudo do marketing dirigido aos proprietários de animais de estimação

A nosso ver, a questão central é a da integração do animal à rotina da família, uma vez que a 'coisa' adquirida, uma vez integrada ao circuito familiar, assume outros significados no seu 'uso' e interação no cotidiano - no caso do animal, a estima e o afeto. As emoções estão inseridas nos atos de compra em que pessoas adquirem os produtos básicos as lembrancinhas para os membros da família (MILLER, 2002). O "animismo mágico" (BOYER, 1996), a identificação e a antropomorfização sentimental (KONECKY, 2007) se faz presente no dia a dia familiar na interação entre pessoais e animais conviventes, integrando as compras para o animal de estimação nas despesas cotidianas da família. Do mesmo modo como o fazem para seus filhos, compram para seus animais alimentos que julgam de marcas confiáveis e de melhor qualidade, gastam com serviços de "cuidadores", creches e passeadores, cuidam de sua higiene, enfeitam seus corpos, amaciam seus pelos, desfrutam de momentos de lazer em comum, cuidam de sua saúde, preocupam-se em garantir sua segurança.

Poderíamos perguntar se animais de estimação estão substituindo as crianças (HILL, GAINES e WILSON 2008; KULICK, 2009) como objeto de devoção (MILLER, 2002) nas famílias das sociedades de consumo. A nosso ver, é uma pergunta simplificadora, uma vez que animais e crianças sempre conviveram em família, sendo muitas vezes adquiridos não somente como companhia, mas como veículos para a construção de autonomia e responsabilidade nos filhos.

Como vimos, em diversos aspectos, os itens de consumo disponíveis aos animais de estimação são similares aos disponíveis seus respectivos proprietários. É possível encontrar similaridade nos itens vinculados à moda, beleza e transformação cosmética típicos da cultura de consumo, disponíveis ao consumo para o embelezamento das mulheres, através dos quais se procura vincular o corpo a uma imagem (FEATHERSTONE, 2010). No caso deste tipo de produtos, podemos inquirir sobre qual imagem estaria o dono do animal se aproximando ao consumir estes produtos, se a sua, a do animal, ou um "outro" (pessoa ou família) idealizado (KULIK, 2009).

É importante refletir também acerca do momento em que as emoções despertadas pelo amor e o desfrute da companhia do animal ultrapassam o limite do prazer e adentram o sofrimento, tanto humano como animal.

A crescente utilização de medicamentos para animais de estimação seria explicada, na visão de um executivo de empresa de medicamentos, pelo fato de que "todas as questões comportamentais que criamos em nós mesmos, estamos agora criando em nossos 
Famílias, animais de estimação e consumo: um estudo do marketing dirigido aos proprietários de animais de estimação

de Lavínia Davis Rangel Pessanha e Roberto Luís da Silva Carvalho

animais de estimação porque eles vivem nos mesmos ambientes (..) que nós." (VLAHOS, 2008:468). Há sofrimento de ambas as partes e o debate nos distintos campos do conhecimento científico não clareou a questão do que é singular, específico ou geral para humanos e para animais. Ademais, percebendo e interagindo com o seu animal como "pessoa" ou membro da família, ou um ser vivo de estima única e especial para si, é que as pessoas possuidoras de animais "problemáticos" ou em sofrimento recorrem aos operadores das especialidades clínicas em busca da "solução" de seus problemas (VLAHOS, 2008).

Diversos sentimentos podem envolver as pessoas e seus animais de estimação. (WALSH, 2009a, 2009b). Há situações traumáticas que provocam sofrimento humano tais como na morte do animal, nas quais o luto decorrente é considerado legítimo. Do mesmo modo, devem ser encaradas como legítimas as dificuldades para superar a perda, desaparecimento ou a separação forçada do animal. Decisões como sacrificar animais em situação de sofrimento são dolorosas para as pessoas e devem ser tratadas com cuidado, tendo em vista os sentimentos de culpa e renúncia envolvidos (WALSH, 2009b).

\section{CONCLUSÕES}

Como foi destacado, as ações de marketing da indústria de cuidados para animais de estimação, visando a comunicação direcionada e indutiva de uma mensagem mercadológica, implicam numa visão simplificada da lógica de consumo e da visão de mundo dos consumidores. O reconhecimento intenção por trás do marketing da indústria não implica que a mesma se reflita na interação entre as pessoas e seus animais de estimação no convívio cotidiano, tal como uma 'resposta' ao 'estímulo induzido' ao consumo de modo 'automático', do tipo relação 'causa e efeito' direto. Encontramos na bibliografia pertinente ao tema diversas evidências de que as motivações das pessoas para o consumo e a aquisição de bens podem ser regidas por outras lógicas, que não aquelas orientadas e pelo marketing.

Aqui há um evidente espaço para pesquisas a ser trabalhado. É importante que se desenvolvam mais estudos sociais e, particularmente, acerca da relação entre as pessoas e seus animais de estimação, pois famílias compostas por pessoas e animais se encontram nas mais distintas classes sociais das sociedades contemporâneas, sendo os vínculos afetivos e emoções despertadas neste relacionamento pouco discutidas na bibliografia de 
Famílias, animais de estimação e consumo: um estudo do marketing dirigido aos proprietários de animais de estimação

de Lavínia Davis Rangel Pessanha e Roberto Luís da Silva Carvalho

ciências humanas latino-americanas.

\section{REFERÊNCIAS BIBLIOGRÁFICAS}

AFONSO, T.; BERDASCO, L.; MEDEIROS, T.; REJOWSKI, M.. "Mercado pet em ascensão - Hotelaria para cães e gatos em São Paulo", in Revista Brasileira de Pesquisa em Turismo, ${ }^{\circ}$. 4, vol. 2, 2008: 102-123.

ARCHER, J. "Why do people love their pets?", in Evolution and Human Behavior, n'. 4, vol. 18, 1997: 237-259.

BARLETT, S. J. "Raízes da Resistência humana aos direitos dos animais: bloqueios psicológicos e conceituais", in Revista Brasileira de Direito Animal, n 2, vol. 3, Salvador, 2007: 17-68.

BELK, R. W. "Possessions and the extended self”, in Journal of Consumer Research, $\mathrm{n}^{\circ} 2$, vol. 15, 1988: 139-168.

BERRY, B. "Interactionism and animal aesthetics: a theory of reflected social power", in Society and Animal, vol. 16, 2008: 75-89.

BEVILAQUA, C. B. “Chimpanzés em juízo: pessoas, coisas e diferenças”, in Horizontes antropológicos, $\mathrm{n}^{\circ} 35$, vol. 17, Porto Alegre, 2011: 65-102.

BOYER, P. "What makes anthropomorphism natural: intuitive ontology and cultural representations", in Journal of the Royal Anthropological Institute, vol. 2 , $\mathrm{n}^{\circ} 1$, 1996: 83-97.

CARCIOFI, A. C.; TESHIMA, E.; BAZOLLI, R. S.; BRUNETTO, M. A.; VASCONCELLOS, R. S.; PEREIRA, G. T.; OLIVEIRA, L. D. "Qualidade e digestibilidade de alimentos comerciais de diferentes segmentos de mercado para cães adultos", in Revista Brasileira de Saúde e Produção Animal, vol. 10, n², 2009: 489-500. Disponível em <http://www.rbspa.ufba.br>. Acesso em 23/07/2009.

CAVANAUGH, L. A.; LEONARD, H. A.; SCAMMON, D. L.. "A tail of two personalities: How canine companions shape relationships and well-being", in Journal of Business Research, vol. 61, n 5, 2008: 469-479.

COHEN, S. P. "Can Pets Function as Family Members?”, in Western Journal of Nursing Research, vol. 24, n $^{\circ}$ 6, 2002: 621-638.

CORNWELL, T. B.; WAMWARA-MBUGUA, L. W.; NICOVICH, S. G. "Dependence patterns in consumer behavior: Exploration and refinement of a concept", in 
Famílias, animais de estimação e consumo: um estudo do marketing dirigido aos proprietários de animais de estimação

de Lavínia Davis Rangel Pessanha e Roberto Luís da Silva Carvalho

Journal of Consumer Behaviour, vol. 7, $\mathrm{n}^{\circ}$ 1, 2008: 51-71.

DOTSON, M. J.; HYATT, E. M. “Understanding dog-human companionship”, in Journal of Business Research, vol. 61, n 5, 2008: 457-466.

EUROPEAN MONITOR INTERNATIONAL. Rising Middle-class Drives Boom in Latin American Pet Care, 2011. Disponível em <http://blog. euromonitor.com/ 2011 /04/rising-middle-class-drives-boom-in-latin-american-pet-care.html>. Acesso em $30 / 05 / 2011$.

FEATHERSTONE, M. "Body, Image and Affect in Consumer Culture”, in Body \& Society, vol. $16 \mathrm{n}^{\circ} 1,2012:$ 193-221

FRANCIONE, G. “Animais como propriedade”, in Revista Brasileira de Direito Animal. Salvador, 2002, $\mathrm{n}^{\circ}$ 2, vol.2, 2007, p13-16.

GOODMAN, D.; SORJ, B.; WILKINSON, J. Da lavoura às biotecnologias: agricultura e indústria no sistema internacional. Tradução Carlos Eduardo Baesse de Souza e Carlos Schlottfeldt. Rio de Janeiro: Campus, 1990.

HARAWAY, D. When the species meet. Minneapolis: University of Minnesota Press, 2008: 425.

HILL, R. P.; GAINES, J. WILSON, R. M. “Consumer behavior, extended-self, and sacred consumption: An alternative perspective from our animal companions", in Journal of Business Research, $\mathrm{n}^{\circ}$ 5, vol. 61, 2008: 553-562.

HOLBROOK. M. B. "Pets and people: Companions in commerce?", in Journal of Business Research, $\mathrm{n}^{\circ}$ 5, vol. 61, 2008: 546-552.

INGOLD, T. "Humanidade e animalidade", in Revista Brasileira de Ciências Socias, vol. 28, 1998. Disponível em <www.anpocs.org.br/portal/publicacoes/rbcs_00_28/ rbcs28_05.htm>. Acesso em 01/03/2010.

KENNEDY, P. F.; MCGARVEY, M. G. “Animal-companion depictions in women's magazine advertising”, in Journal of Business Research, n 5, vol. 61, 2008: 424430.

KEELEY, B. L. "Anthropomorphism, primatomorphism, mammalomorphism: understanding cross-species comparisons", in Biology and Philosophy, $\mathrm{n}^{\circ} 4$, vol. 19, 2004: 521-540.

KONECKI, K. T. "Pets of Konrad Lorenz. Theorizing in the social world of pet owners", in Qualitative Sociology Review, n. 1, vol. 3, 2007: 110-127.

KULICK, D. “Animais gordos e a dissolução da fronteira entre as espécies”, in $M A N A, \mathrm{n}^{\circ}$ 
Famílias, animais de estimação e consumo: um estudo do marketing dirigido aos proprietários de animais de estimação

de Lavínia Davis Rangel Pessanha e Roberto Luís da Silva Carvalho

2. vol. 15, 2009: 481-508.

LATOUR, B. Jamais fomos modernos. São Paulo: Editora 34, 1994.

LEITE, F. "Donos perdem vergonha de fazer festa de aniversário para seus cães", in Folha de São Paulo, São Paulo, 19/5/2007. Disponível em: Disponível em <http://www1.folha.uol.com.br/folha/equilibrio/noticias/ult263u4494.shtml>. Acessado em 07/03/2011.

MILLER, D. Teoria das compras: o que orienta as escolhas dos consumidores. São Paulo: Nobel, 2002.

MOSTELLER, J. "Animal-companion extremes and underlying consumer themes", in Journal of Business Research, $\mathrm{n}^{\circ}$ 5, vol. 61, 2008: 512-521.

NAST, H. J. "Loving....whatever: alienation, neoliberalism and pet-love in the twenty-first century", in ACME: An International E-Journal for Critical Geographies, $\mathrm{n}^{\circ} 2$, vol.5, 2006a: 300-327.

NAST, H. J. “Critical Pet Studies?”, in Antipode, n 5, vol.38, 2006b: 894-906.

OLIVEIRA, S. B. C. Sobre homens e cães: um estudo antropológico sobre afetividade, consumo e distinção. Rio de Janeiro, 2006. In Dissertação (Mestrado em Sociologia e Antropologia). IFCS/PPGSA, Universidade Federal do Rio de Janeiro, 2006.

OLIVEIRA, C. B. D.; OLIVEIRA, C. R. "A nova realidade do marketing farmacêutico veterinário: uma estratégica B2B para o sucesso da linha pet”, in eGesta, n², vol.3, 2007: 23-43.

PANKSEPP, J. “Affective consciousness: Core emotional feelings in animals and humans”, in Consciousness and Cognition, $\mathrm{n}^{\circ}$ 1, vol. 14, 2004: 30-80.

PETTY, R. D. "Pet peeves: trademark law and the consumer enjoyment of brand pet parodies", in The Journal of Consumer Affairs, $\mathrm{n}^{\circ} 3$, vol. 42, 2008: 461-470.

REES, A. "Reflections on the field: primatology, popular science and the politics of personhood", in Social Studies of Science, n ${ }^{\circ}$, vol. 37, 2007: 881-907.

ROCHA, A. CHRISTENSEN, C. Marketing: teoria e prática no Brasil. São Paulo: Atlas, 2008 .

SANDERS, C. R. "The animal "other": self definition, social identity and companion animals", in Advances Consumer Research, vol.17, 1990: 662-668.

SERPELL, J. A. "Anthropomorphism and Anthropomorphic Selection-Beyond the "Cute Response"”, in Society \& Animals, $\mathrm{n}^{\circ}$ 1, vol. 11, 2003: 83-100. 
Famílias, animais de estimação e consumo: um estudo do marketing dirigido aos proprietários de animais de estimação

de Lavínia Davis Rangel Pessanha e Roberto Luís da Silva Carvalho

SHELL, M. “The Family Pet”, in Representations, n. 15: 121-153, 1986.

SINGER, P. Libertação Animal. São Paulo: Lugano, 2004.

SILVA, R. C. M. "A teoria da pessoa de Tim Ingold: mudança ou continuidade nas representações ocidentais e nos conceitos antropológicos?", in Horizontes antropológicos, $\mathrm{n}^{\circ}$ 35, vol. 17, Porto Alegre, 2011.

SOARES, R. S.; CARVALHO, D. T. "Diferenças entre bases de segmentação dos mercados consumidores de uma linha de produtos para pets", in Revista Eletrônica de Administração, $\mathrm{n}^{\circ}$ 3, vol.10, 2004: 1-19. Disponível em <http://read. adm.ufrgs.br/edicoes/pdf/artigo_70.pdf>. Acesso em 26/07/2010.

THOMAS, K. O homem e o mundo natural: mudança de atitude em relação às plantas $e$ aos animais, 1500-1800. São Paulo: Companhia das Letras, 2001.

VLAHOS, J. “Animais de estimação movidos a drogas”, in Revista Latinoamericana de Psicopatologia Fundamental, $\mathrm{n}^{\circ}$ 3, vol.11, São Paulo, 2008: 449-469.

WALSH, F. "Human-animal bonds I: the relational significance of companion animals", in Family Process, $\mathrm{n}^{\circ}$ 4, vol. 48, 2009a: 462-480.

WALSH, F. "Human-animal bonds II: the role of pets in family systems and family therapy", in Family Process, n 4, vol. 48, 2009b: 481-499.

WOLCH, J.; EMEL, J. "Witnessing the Animal Moment", in, Jennifer Wolch and Jody Emel (eds.), Animal Geographies: Place, Politics, and Identity in the NatureCulture Borderlands. London and New York: Verso, 1998: 1-23.

Artigo submetido: 22/02/2013

Artigo aprovado: 09/11/2014 